\title{
Could patents interfere with the development of a cardiovascular polypill?
}

\author{
Reed F. Beall ${ }^{1,2,3^{*}}$, Jon-David R. Schwalm ${ }^{4}$, Mark D. Huffman ${ }^{5}$, Tara McCready ${ }^{4}$, Salim Yusuf ${ }^{4}$ and Amir Attaran ${ }^{1,2,3}$
}

\begin{abstract}
Background: The Wellcome Trust, the World Health Organization, and cardiologists have advocated for the idea of a "polypill" containing multiple cardiovascular drugs to be co-formulated into a single pill for over a decade. Some cardiologists have asserted that the drugs commonly considered for inclusion into such a polypill are older and therefore free of patent protection. We tested this assertion. This project was requested by the World Heart Federation (WHF).

Methods, data and materials: Two cardiologists from the WHF provided a list of 48 cardiovascular drugs for evaluation. We designated the United States and Canada as the base jurisdictions for this patent study. We linked patent data from these countries' national medicine patent registers to patent information in over 96 other countries using Derwent and INPADOC via Thomson Innovation. We expanded our study beyond the aforementioned data linkage through a systematic search of the World Intellectual Property Organization's PatentScope, which was based primarily upon the drugs' active ingredient names.

Results: In the United States and Canada, eight of the drugs were only available in the patent-protected, brand name formulation in one or both countries. Another 21 drugs had relevant patents, but generic equivalents were nevertheless available. Only 19 drugs (40 \%) appeared entirely post-patent. Broadening the co-formulation searches globally, the overwhelming majority of drugs (40/48) were mentioned in patent applications for cardiovascular drug combinations.

Conclusion: The assertion that most of these cardiovascular drugs are post-patent is accurate, but only in the sense that many of the original patents on these active ingredients have expired and that generic alternatives are usually available. The landscape of patents covering novel (co-) formulations is far more complex, however. Most research and development for cardiovascular combination medicines are likely to be undertaken by companies whose original patents on the active ingredient will soon expire or have recently expired. Cardiologists looking to accelerate polypill development may consider approaching such companies to partner.
\end{abstract}

\section{Background}

There is a major gap between the prevalence of hypertension, and recourse to effective treatment, particularly in developing countries, where $80 \%$ of the disease burden lies $[1,2]$. To address this, many have called for simplifying both the prescribing of and adherence to treatment by co-formulating (i.e., combining) several drugs into a single "polypill," rather than 3-7 pills taken individually [3-6]. Triple and even quadruple co-formulations have

\footnotetext{
*Correspondence: reedbeall@gmail.com

${ }^{3}$ Faculties of Medicine, University of Ottawa, One Stewart St, Ottawa, ON K1N 6N5, Canada

Full list of author information is available at the end of the article
}

been developed for conditions such as HIV/AIDS and tuberculosis, and are credited with improved treatment outcomes $[7,8]$. A number of clinical trials $[2,9,10]$ and meta-analyses $[11,12]$ of different polypill co-formulations suggest that the same strategy can be helpful for the treatment of hypertension and for the primary and secondary prevention of cardiovascular disease (CVD) $[13,14]$. A polypill can also improve patient adherence, and it can reduce the risk of adverse drug interactions in patients taking multiple medications [15]. Given the potential to reduce cardiovascular events and the associated cost of care, public investment into the development of a polypill has been shown to be cost-effective [16]. 
Indeed, the World Health Organization has been calling for the development of a polypill for over a decade [17].

But while there is large appetite from the public health community for a polypill, no such thing is commonplace in today's global pharmaceutical market. Why is this? Are there patent barriers to market entry? Experts on the treatment of CVD have stated that the drugs under consideration for inclusion in cardiovascular polypill prototypes are no longer covered by patents $[3,6,18]$, but this presumption has not been rigorously tested. A very recent study was published that investigated the patent situation on five cardiovascular medicines in the United States and Europe, but did not extend beyond these drugs and geographic regions [19]. Several publications, both academic $[4,20]$ and otherwise $[21,22]$, have rightly called for a broad and global understanding of the polypill patent situation. This article is intended to address this need. It is written for a broad audience while bearing in mind that this project was undertaken at the request of the World Heart Federation (WHF).

\section{Methods, supporting materials, and data availability}

We began by independently consulting two expert cardiologists (JDRS, MDH) - who both participated in a workshop on the polypill endorsed by the WHF-on what drugs are of particular interest for co-formulating. We used the union of their drug lists ( $n=48$ drugs) as the focal point for this patent study.

As patent grants vary by country, it is necessary to designate a base legal jurisdiction for patent studies as a starting point for analysis. Consistent with other published methodologies [23-29], we set the United States and Canada as our base jurisdictions because medicine patents are uniquely prevalent there. These countries have large pharmaceutical markets, grant a high number of patents annually, and have strong infrastructure for enforcing those patents, making them particularly attractive for pharmaceutical suppliers.

Both countries have publicly available medicine patent registers-the United States Food and Drug Administration's Orange Book [30] and Health Canada's Patent Register [31] - that allow users to search by active ingredient name. We therefore searched by each active ingredient name in each database and then recorded the patent information retrieved, if any. We also recorded whether an equivalent generic product was available on the market for each drug using the Orange Book [30] and Health Canada's Drug Product Database [32]-that is to say, whether the product had already been "genericized" in the United States and Canada respectively. We considered an equivalent to be a generic product with the identical active ingredient(s), (co-)formulation, and strength as the brand name one in question (i.e., the originator's patented version).

Next, we consulted two commercial-grade international patent search databases covering over 96 countries-INPADOC [33] and Derwent [34] - via Thomson Innovation [35]. These databases group patent filings into "patent families" (i.e., sets of related patents), which is either done automatically by their relationship to an original priority application (as is the case in INPADOC [36]) or is done manually by patent analysts (as is the case in Derwent). Using the union of the patent family groupings of INPADOC and Derwent adds to the robustness of studies such as these, both in terms of the type of patents covered and the countries covered by them [23]. We entered the American and Canadian patent data from those North American medicine patent registers into Thomson Innovation and retrieved the international patent families for each drug. Reasoning that patent protection for each application is unlikely to extend longer than the standard 20-year period, we removed all patents with application filing dates earlier than 1 January 1995.

Thereafter, we reviewed the title and abstract of each "Basic" patent identified by Derwent (i.e., a patent representing the typical one contained within each family). We scored the type of protections typically covered by the patents contained in each family according to their proposal of a new co-formulation (i.e., drug combinations), a new compound (i.e., the active ingredient), a new formulation (e.g., extended release tablet or capsule), a new method of treatment (i.e., using the drug to treat specific conditions), and/or a new manufacturing process.

Both a strength and limitation of the above method is that all patents included are related to currently marketed products. To provide an impression of potentially relevant patent literature that may have been excluded, we conducted supplemental searches in the World Intellectual Property Organization's (WIPO) PatentScope database [37]. This database contains applications filed by those seeking protection in many or all of the 148 national signatories to the Patent Cooperation Treaty. We built search algorithms to capture patent applications on combinations of the drugs on our list of 48 medicines. Our search protocols are included Additional file 1: Appendix S1.

All of the above patent searches were performed in May and June 2015. Note that there is no objective, definitive point at which such searches have identified all relevant patents. An expert judgment has to be made when to stop. Our results therefore should be taken as a preliminary appraisal, reflecting our search strategy, and should not be regarded by anyone seeking to commercialize 
these drugs as a substitute for obtaining independent legal advice. Our raw datasets are available in this article's supplementary materials (Additional file 2).

\section{Results}

The drugs' patent/genericized status as single formulations in the United States and Canada

We found that eight of the 48 drugs (17\%) were available only as a brand name, patent-protected formulation in one of the base jurisdictions (the United States or Canada) (see Fig. 1). Olmesartan was the only drug available exclusively in the brand name in both countries.

Also shown in Fig. 1 are the 16 drugs (33\%) for which relevant patents were located in the United States or Canada, but had nevertheless been genericized. As for the remaining cardiovascular drugs ( 24 of 48 or $50 \%$ ), we located no valid patents and observed that the markets had indeed been genericized.

\section{The drugs' patent/genericized status as co-formulations in the United States and Canada}

As for fixed-dose combination (FDC) products containing one or more of the 48 drugs of interest, we found ten drugs (21\%) for which the only co-formulation(s) available in the United States or Canada was the patent-protected, brand name product (see Fig. 2). An additional ten drugs $(21 \%)$ were contained in one or more patented-protected FDCs, but had been genericized. For the majority of the cardiovascular drugs ( 28 of 48 , or $58 \%$ ) investigated, however, we either located no patents using our methodology or observed that no co-formulations containing the drug in question were on the market.

\section{Patent filings by type of protection and by country}

Table 1 shows the type of protections covered by the patent filings contained in the INPADOC and/or Derwent international patent families relating to the relevant US or Canadian marketed products in question. Patent protection on these drugs' active ingredients was rare, but in some cases, not all patents had expired globally, even in North America.

By far, the most common type of protection afforded by these drugs' respective patent families pertained to novel formulations or co-formulations. Patents applying to these categories were nearly five times more prevalent as compared to those on the active ingredient. Patents on

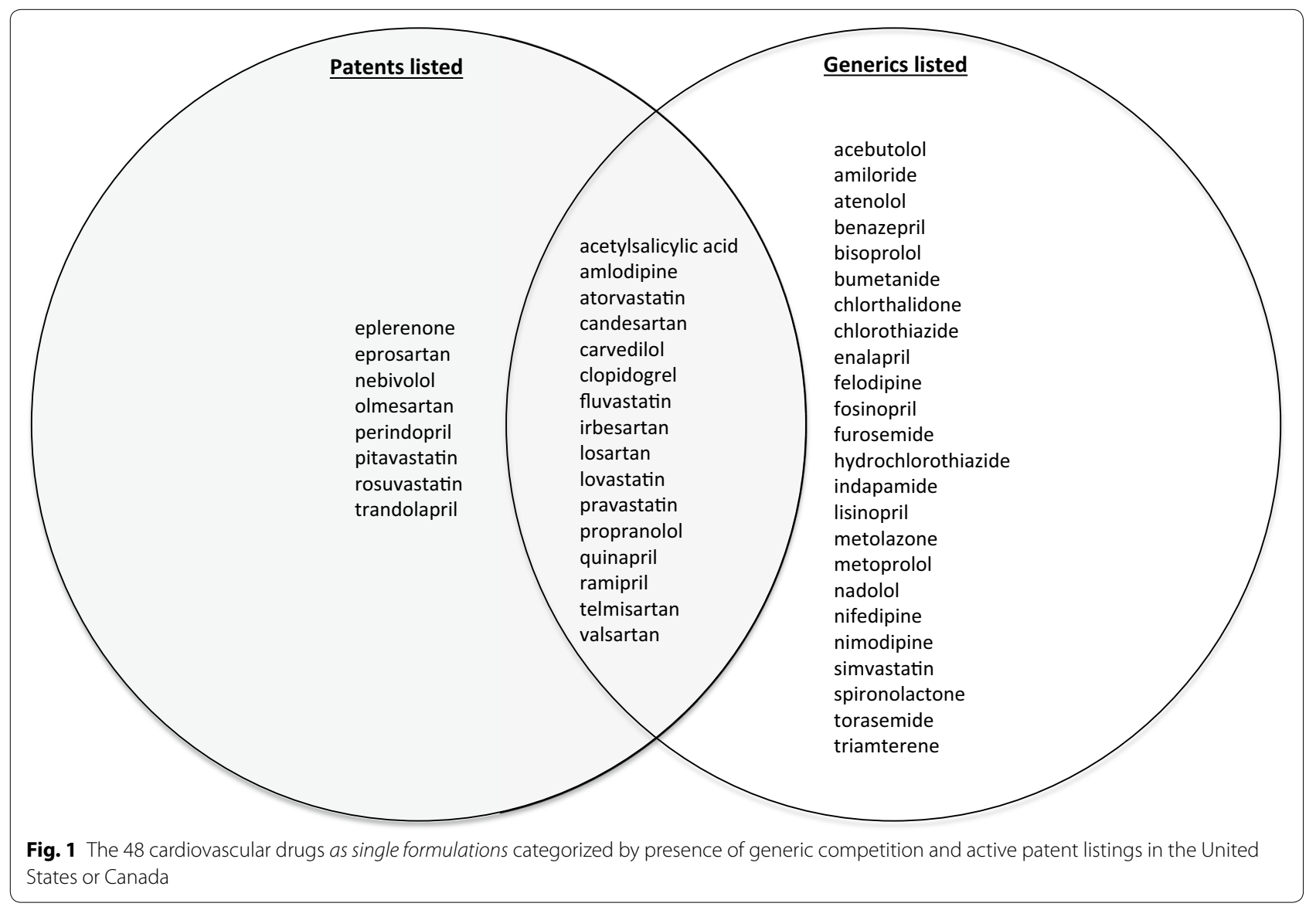




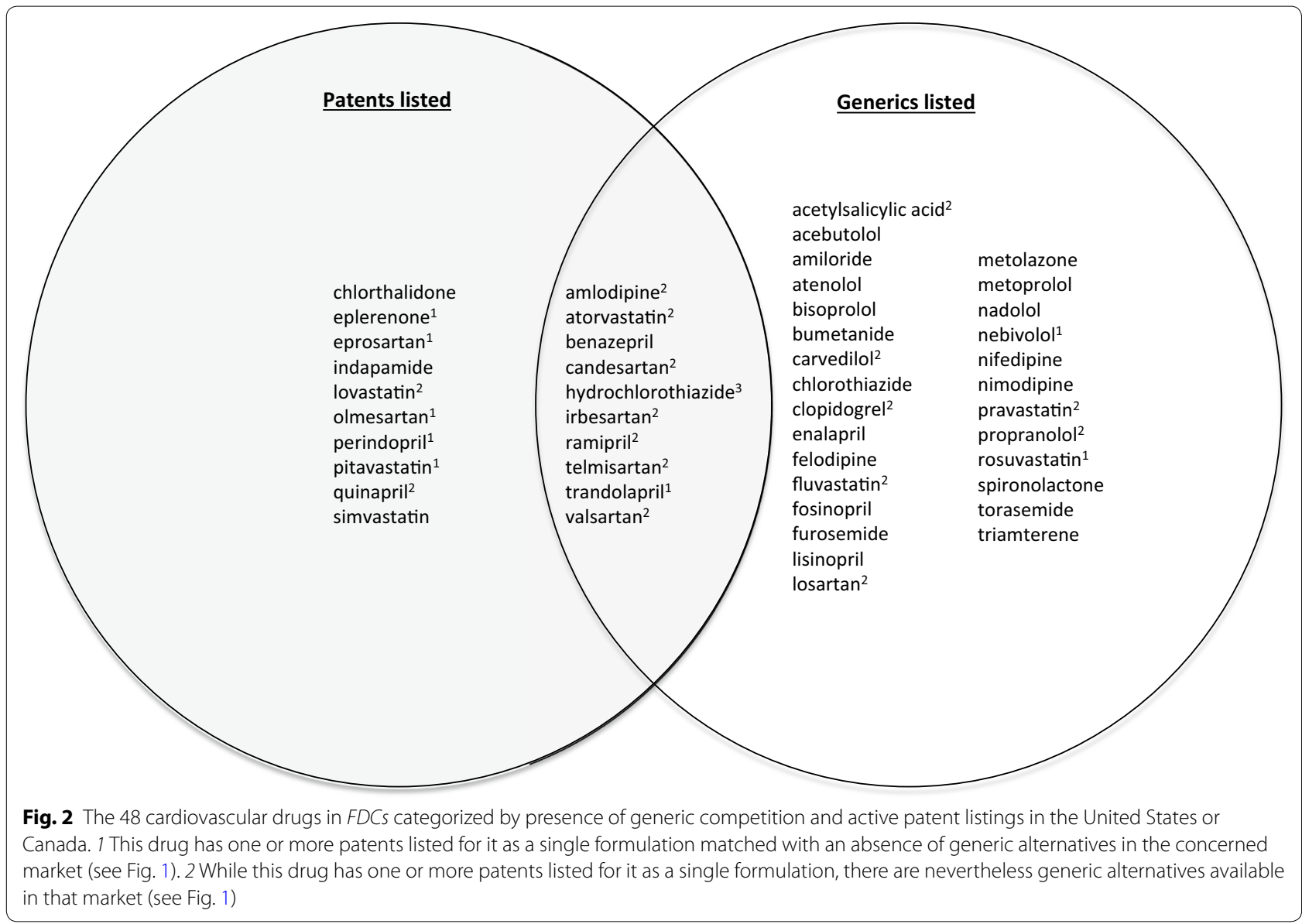

using the drug as a method of treatment for cardiovascular disease or on a manufacturing process were also much more common than those on the active ingredient.

Nevertheless, as is shown in Table 1, we found no patents of any type whatsoever on 19 of these drugs in the United States and Canada, which cover all drug classes identified by the WHF cardiologists (i.e., statins, antiplatelets, angiotensin converting enzyme inhibitors, angiotensin II receptor blockers, calcium channel blockers, beta blockers, and diuretics).

\section{Searching for polypill co-formulation patents globally: WIPO PatentScope}

Finally, to extend our analysis beyond the patents related to those listed in the American and Canadian medicine patent registers, we searched WIPO PatentScope for all patent applications that mention combinations of drugs within our list of 48 cardiovascular medicines. (see Additional file 1: Appendix S2 for four common approaches that we observed applicants had taken to construct their patent applications for cardiovascular FDCs.)

The overwhelming majority of the drugs (40 of 48 , or $83 \%)$ were identified in the co-formulation patent applications returned from WIPO PatentScope, either by active ingredient name or by drug class. Only eight drugs were unmentioned, all of which were older diuretics (amiloride, bumetanide, chlorthalidone, eplerenone, furosemide, metolazone, spironolactone, torasemide, triamterene). The remaining 3 (chlorothiazide, hydrochlorothiazide, indapamide) were identified as the diuretic of choice in many proposed co-formulations, especially hydrochlorothiazide.

\section{Discussion}

Cardiologists' perception $[3,6,18]$ that the drugs being considered for CVD polypill co-formulations are post-patent has some empirical merit, but only in the sense that many of the original patents on the active ingredient(s) have expired and that the majority of these drugs have been genericized. This overlooks, however, that other forms of patent protection (i.e., formulation, co-formulation, method of treatment, manufacturing process) are more prevalent and can carry on for years after the expiration of the original patents on the active ingredient(s). We found that only 19 of the 48 drugs (40\%) were totally patent free in the base jurisdictions 


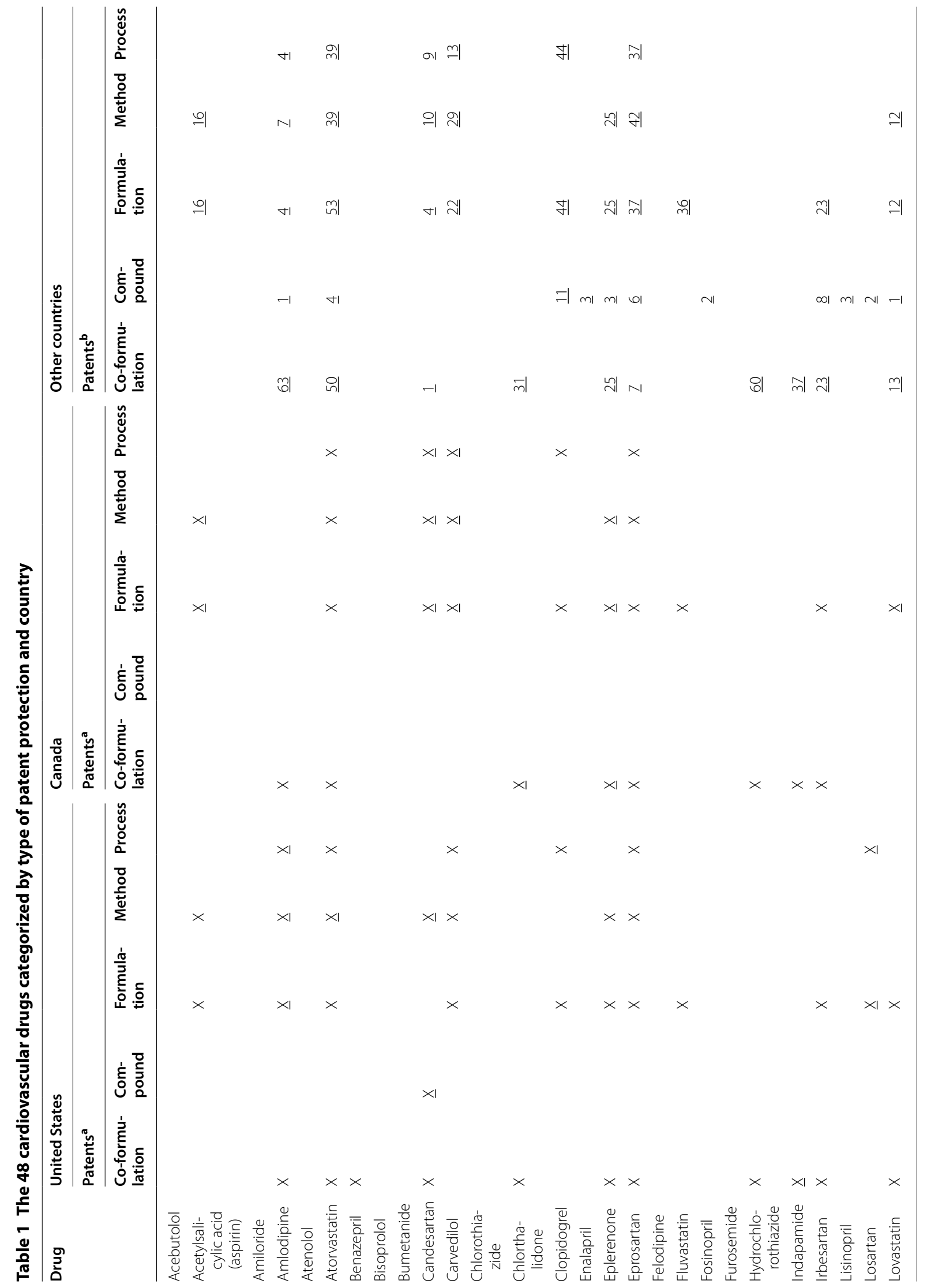




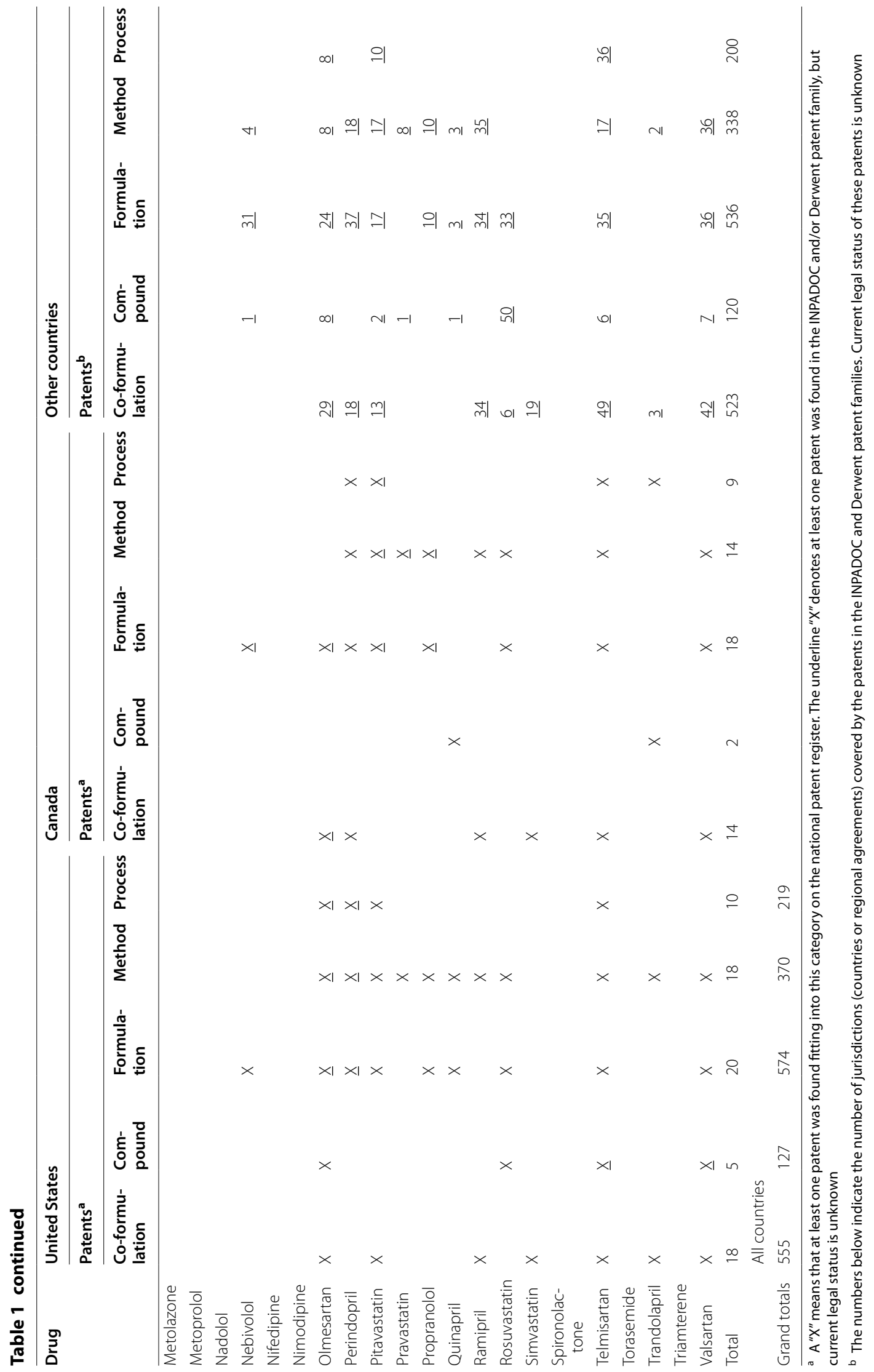


according to our methodology (see Table 1) and that most of the drugs ( 40 of 49 , or $83 \%$ ) could be found on co-formulation patent applications filed through WIPO. When these secondary tiers of patenting are taken into account, it is more common to find patent filings than none whatsoever.

What is the significance of this finding for polypill advocates like the WHF who see promise in that treatment in developing countries? Below we discuss two perspectives on the patent system-for shorthand, the "competitive" versus "cooperative" perspectives-which differently inform two corresponding courses of action based on the findings and data presented in this report.

The "competitive" perspective is that patents represent strong, if temporary, barriers for others seeking to develop a technology and disseminate it widely. Patent owners possess exclusive rights to seek financial compensation in the law courts from those who infringe their technology. In this perspective, advocates of a CVD polypill should be prepared to deal with risk adverse pharmaceutical companies, who would likely not want to develop products that infringe upon these rights. Any patent is therefore a disincentive.

Based on this view of the patent system, our results, such as those in Table 1, may be read as a road map of existing obstacles to polypill co-formulating, while the non-shaded areas of Figs. 1 and 2 represent the patentfree freedom to operate. One could, then, work within the latter subset to propose a new cardiovascular FDC, which dodges the patent barriers. In doing so, advocates would be well advised to work with pharmaceutical firms with proven track records in the chemistry, manufacturing and controls aspects of making pharmaceuticals and with experience obtaining product registration. While all the major pharmaceutical companies have these capacities, some generics firms do as well. As of writing, one generics company (Ferrer) is already making FDCs that meet the requirements of stringent regulatory authorities in Europe, as are several India-based firms albeit without satisfying stringent regulatory authority standards [17, 38].

The "cooperative" perspective is that the patent system serves to incentivize new innovation, products and commercial activities. Patent owners acquire rights so as to make a business case for investment and commercialization. In this perspective, advocates of a CVD polypill should try to piggyback onto efforts that maximize the revenue pharmaceutical companies can obtain from their patent holdings, but in such a way that allowances are made for access to medicines in poorer countries.

Based on this view of the patent system, the shaded areas of Figs. 1 and 2 represent not barriers, but opportunities, because the patent holder's monopoly brings with it a company that already has solved the technical and regulatory issues of their patented drug, and likely has the wherewithal and business interest to drive forward a new FDC including that drug. Indeed, evidence shows that companies become most receptive to develop new co-formulations as primary patents come close to expiring, so as to extend (or "evergreen") market exclusivity [39]. See Table 2 for the age original patents on the active ingredients of the 48 drugs' in descending order according to the Merck index [40]. There is empirical evidence that co-formulating is already happening for the most recently expired patents on the active ingredients: Daiichi Sankyo has recently introduced Tribenzor (amlodipine + hydrochlorothiazide + olmesartan), and Novartis has introduced Exforge HCT (the same, but substituting valsartan for olmesartan). Advocates would be well advised to create mutually beneficial arrangements with the pharmaceutical companies whose original patents on the active ingredient are drawing to an end, both to innovate polypills, and to bring these to market in developing countries at an affordable price. A clear lesson learned from the global campaigns for access to HIV/ AIDS, malaria and other medicines is that companies can reconcile revenue maximization in rich countries with reduced revenue expectations or even philanthropic concessions in poor countries. They can do this by outlicensing their patents in the latter, refraining from enforcing their patents in certain regions, and/or offering substantial price reductions based on ability to pay (tiered pricing) [41-45]. Whatever access strategy is chosen, patents can be actively managed to serve as springboards for access campaigns, rather than managed as just barriers.

We do not consider the "cooperative" and "competitive" scenarios mutually exclusive; rather they are complementary and should both be pursued. But both of them require that advocates make it extremely clear exactly which medicine combinations are best for an FDC. That choice has to be based on strong scientific consensus of the most clinically rational combinations, but not necessarily unanimity, and must strike a balance between the best therapeutic outcomes (for patient treatment success) and widespread suitability of the formulation (for population health coverage). Clear consensus is a true sine qua non, because whether seen through the eyes of a branded or generic company, advocates are calling on them to invest millions of dollars in FDC development and registration-and very simply put, companies will only sink that money when there is consensus guidance that says "the combination of A plus B plus C is satisfactory", rather than equivocal guidance that says "the combination of $\mathrm{A}$ or $\mathrm{B}$, plus $\mathrm{C}$ or $\mathrm{D}$, plus $\mathrm{E}$ or $\mathrm{F}$, but not if $\mathrm{F}$ is combined with C". 
Table 2 Merck index active ingredient patent listing for the 48 cardiovascular drugs

\begin{tabular}{|c|c|c|c|}
\hline INN & $\begin{array}{l}\text { Latest patent grant } \\
\text { year provided }\end{array}$ & $\begin{array}{l}\text { International INPADOC } \\
\text { family application date range }\end{array}$ & Patent numbers provided \\
\hline Olmesartan & 1997 & 1992-2011 & EP503785, US5616599 \\
\hline Valsartan & 1995 & $1991-2010$ & EP443983, US5399578 \\
\hline Candesartan & 1993 & $1991-2006$ & EP459136, US5196444 \\
\hline Eprosartan & 1993 & 1990-2001 & EP403159, US5185351 \\
\hline Irbesartan & 1993 & 1990-1999 & WO9114679, US5270317 \\
\hline Atorvastatin & 1993 & 1990-2007 & EP409281, US5273995 \\
\hline Rosuvastatin & 1993 & 1992-2003 & EP521471, US5260440 \\
\hline Losartan & 1992 & 1987-1999 & EP253310, US5138069 \\
\hline Telmisartan & 1992 & $1991-2011$ & EP502314 \\
\hline Fosinopril & 1991 & 1988-1995 & EP 304063, US5011930 \\
\hline Pitavastatin & 1991 & 1988-1995 & EP304063, US5011930 \\
\hline Trandolapril & 1990 & $1981-1994$ & EP84164, US4933361 \\
\hline Clopidogrel & 1989 & 1982-1998 & $\begin{array}{l}\text { EP99802, US4529596, EP281459, } \\
\text { US4847265 }\end{array}$ \\
\hline Fluvastatin & 1988 & 1983-1995 & WO8402131, US4739073 \\
\hline Nebivolol & 1987 & 1984-2004 & EP145067, US4654362 \\
\hline Ramipril & 1986 & 1982-1994 & EP79022, US4587258 \\
\hline Amlodipine & 1986 & 1983-1998 & EP89167, US4572909 \\
\hline Perindopril & 1985 & 1979-1993 & EP49658, US4508729 \\
\hline Carvedilol & 1985 & 1978-1994 & DE2815926, US4503067 \\
\hline Eplerenone & 1985 & 1984-2004 & EP122232, US4559332 \\
\hline Simvastatin & 1984 & 1980-1994 & EP33538, US4444784 \\
\hline Benazepril & 1983 & 1982-1993 & EP72352, US4410520 \\
\hline Enalapril & 1983 & 1979-1998 & EP12401, US4374829 \\
\hline Lisinopril & 1983 & 1979-1998 & EP12401, US4374829 \\
\hline Quinapril & 1982 & $1981-1996$ & EP49605, US4344949 \\
\hline Pravastatin & 1982 & 1980-1996 & DE3122499, US4346227 \\
\hline Felodipine & 1981 & 1978-1994 & EP7293, US4264611 \\
\hline Bisoprolol & 1981 & 1976-1993 & BE859425, US4258062 \\
\hline Lovastatin & 1980 & 1978-1998 & US4231938 \\
\hline Torasemide & 1977 & 1974-1994 & DE2516025, US4018929 \\
\hline Metoprolol & 1976 & 1932-1977 & DE2106209, US3998790 \\
\hline Nadolol & 1976 & $1971-1979$ & DE2258995, US3935267, DE2421549 \\
\hline Nimodipine & 1974 & $1971-1977$ & DE2117571, US3799934 \\
\hline Acebutolol & 1974 & 1967-1974 & ZA6808345, US3857952 \\
\hline Atenolol & 1974 & 1969-1975 & DE2007751, US3663607, US3836671 \\
\hline Bumetanide & 1974 & 1968-1974 & DE1964503, DE1964504, US3806534 \\
\hline Indapamide & 1971 & 1968-1969 & FR2003311, US3565911 \\
\hline Propranolol & 1970 & 1962-1967 & $\begin{array}{l}\text { BE640312, BE640313, US3337628, } \\
\text { US3520919 }\end{array}$ \\
\hline Nifedipine & 1969 & 1967-1969 & ZA6801482, US3485847 \\
\hline Amiloride & 1967 & 1962-1981 & BE639386, US3313813 \\
\hline Metolazone & 1967 & 1966-1967 & US3360518 \\
\hline Acetylsalicylic acid (aspirin) & 1966 & 1959-1964 & DE236196, US2890240, US3235583 \\
\hline Hydrochlorothiazide & 1964 & $1962-1965$ & $\begin{array}{l}\text { US3025292, US3163645, DE1163332, } \\
\text { US3164588, US3043840 }\end{array}$ \\
\hline Triamterene & 1963 & 1960-1964 & US3081230 \\
\hline Chlorthalidone & 1962 & 1957-1962 & US3055904 \\
\hline Furosemide & 1962 & 1959-1964 & DE1122541, US305888 \\
\hline Spironolactone & 1961 & $1960-1961$ & US3013012 \\
\hline Chlorothiazide & 1957 & 1957 & US2809194 \\
\hline
\end{tabular}


The endorsement of advocates, or a coalition of advocates, to recommend a particular CVD co-formulation would likely appeal to drug makers and have a very significant impact on their willingness to invest. Since one would be endorsing a choice of co-formulation, and not a product, there is no conflict of interest in doing so. That would be a valuable step, whether pursuing a FDC built upon the "competitive" viewpoint of selecting only unpatented drugs over which nobody has exclusivity, or upon the "cooperative" viewpoint of selecting a drug precisely because it is patented and somebody has exclusivity. Our previous research in bringing low-cost new medicines to developing countries has shown that, depending upon circumstances, patent-centered strategies for improving access to medicines can be just as effective as patentnegating ones [41, 46, 47].

\section{Conclusion}

Our study has tested the assertion that the drugs under consideration for polypill co-formulating are older, are post-patent, and have been genericized. For the original active ingredient patents, this is largely true, but our findings show that secondary patenting on these medicines is prevalent, and this includes large numbers co-formulation patents by generic and brand name companies alike.

We have suggested two strategies based on the empirical data provided by this study for global public health entities like the WHF who are in pursuit of developing a polypill, and these strategies can be undertaken simultaneously. Our impression, however, is that others attempting to advance polypill development have relied most heavily upon variants of the first strategy. We suggest a more balanced approach, set upon two parallel tracks, in which patents are viewed both as barriers and as opportunities, depending who the commercial partner is.

\section{Additional files}

Additional file 1. Appendix S1. Co-formulation search criteria in WIPO PatentScope (run in May 2015). Appendix S2. Typology of search results from co-formulation searches in WIPO PatentScope.

Additional file 2. Cardiovascular drug patent database.

\section{Abbreviations}

CVD: Cardiovascular disease; FDC: Fixed-dose combination; INPADOC: INternational PAtent DOCumentation database, which is maintained by the European Patent Office; HIV/AIDS: Human immunodeficiency virus infection and acquired immune deficiency syndrome; WHF: The World Heart Federation; WIPO: The World Intellectual Property Organization.

\section{Authors' contributions}

RFB, SY, and AA conceived and designed the study. RFB, JDRS, MDH collected the data. RFB and AA analyzed the data. RFB wrote the first draft of the manuscript. All authors contributed to revising the manuscript. All authors read and approved the final manuscript.

\section{Author details}

1 Population Health Program, University of Ottawa, One Stewart St, Ottawa, ON K1N 6N5, Canada. ${ }^{2}$ Faculties of Law, University of Ottawa, One Stewart St, Ottawa, ON K1N 6N5, Canada. ${ }^{3}$ Faculties of Medicine, University of Ottawa, One Stewart St, Ottawa, ON K1N 6N5, Canada. ${ }^{4}$ Population Health Research Institute (PHRI), Hamilton Health Sciences, McMaster University, 237 Barton Street East, Hamilton, ON L8L 2X2, Canada. ${ }^{5}$ Feinberg School of Medicine, Northwestern University, Arthur J. Rubloff Building, 420 East Superior Street, Chicago, IL 60611, USA.

\section{Acknowledgements}

Authors declare that each of their roles in the development of this manuscript satisfies the ICMJE criteria for authorship. No direct funding was received specific to this manuscript; however, this article is relevant to RFB's doctoral studies, which have been funded through a Vanier Doctoral Scholarship by the Canadian Institutes of Health Research (CIHR) of the Government of Canada.

\section{Competing interests}

JDS, TM, and SY have declared that PHRI receives funding for investigating the polypill from Cadila, but the authors have not received any personal compensation, stocks or share or employment with Cadila or any other company. SY received an honorarium and travel expenses once to attend a meeting in the last 5 years. SY is listed as an inventor on patents relating to the treatment of cardiovascular disease. $\mathrm{MDH}$ receives support from the World Heart Federation to serve as its senior program advisor for its Emerging Leaders program, which is funded by unrestricted educational grants from AstraZeneca, Boehringer Ingelheim, and Bupa. All other authors (RFB and AA) have nothing to declare.

Received: 5 June 2016 Accepted: 2 August 2016

Published online: 18 August 2016

\section{References}

1. Yusuf S, Wood D, Ralston J, Reddy KS. The World Heart Federation's vision for worldwide cardiovascular disease prevention. Lancet. 2015;386(9991):399-402.

2. Yusuf S, Islam S, Chow CK, Rangarajan S, Dagenais G, Diaz R, et al. Use of secondary prevention drugs for cardiovascular disease in the community in high-income, middle-income, and low-income countries (the PURE Study): a prospective epidemiological survey. Lancet. 2011;378(9798):1231-43.

3. Wald NJ, Law MR. A strategy to reduce cardiovascular disease by more than $80 \%$. BMJ. 2003;326(7404):1419.

4. Ross M. The combination drugs debate: unstable and unpatentable. Pharm Technol Eur. 2009;21(9).

5. Katsnelson A. Polypill improves adherence but fails to win all scientists' hearts. Nat Med. 2013;19(10):1192.

6. Lafeber M, Spiering W, Singh K, Guggilla RK, Patil V, Webster R. The cardiovascular polypill in high-risk patients. Eur J Prev Cardiol. 2012;19(6):1234-42.

7. Calmy A, Pinoges L, Szumilin E, Zachariah R, Ford N, Ferradini L, et al. Generic fixed-dose combination antiretroviral treatment in resource-poor settings: multicentric observational cohort. AIDS. 2006;20(8):1163-9.

8. Blomberg B, Spinaci S, Fourie B, Laing R. The rationale for recommending fixed-dose combination tablets for treatment of tuberculosis. Bull World Health Organ. 2001;79:61-8.

9. Group PC. An international randomised placebo-controlled trial of a fourcomponent combination pill ("polypill") in people with raised cardiovascular risk. PLoS One. 2011;6(5):e19857.

10. Indian Polycap Study (TIPS). Effects of a polypill (polycap) on risk factors in middle-aged individuals without cardiovascular disease (TIPS): a phase II, double-blind, randomised trial. Lancet. 2009;373(9672):1341-51.

11. Elley CR, Gupta AK, Webster R, Selak V, Jun M, Patel A, et al. The efficacy and tolerability of 'polypills': meta-analysis of randomised controlled trials. PLoS One. 2012;7(12):e52145.

12. Gupta AK, Arshad S, Poulter NR. Compliance, safety, and effectiveness of fixed-dose combinations of antihypertensive agents: a meta-analysis. Hypertension. 2010;55(2):399-407. 
13. Bangalore S, Kamalakkannan G, Parkar S, Messerli FH. Fixed-dose combinations improve medication compliance: a meta-analysis. Am J Med. 2007;120(8):713-9.

14. Huffman MD. The polypill: from promise to pragmatism. PLoS Med. 2015;12(8):e1001862.

15. Sleight $P$, Pouleur $H$, Zannad F. Benefits, challenges, and registerability of the polypill. Eur Heart J. 2006;27(14):1651-6.

16. Wald NJ, Luteijn JM, Morris JK, Taylor D, Oppenheimer P. Cost-benefit analysis of the polypill in the primary prevention of myocardial infarction and stroke. Eur J Epidemiol. 2016;31(4):415-26. doi:10.1007/ s10654-016-0122-1.

17. Webster R, Rodgers A. Priority medicines for Europe and the World "A public health approach to innovation": background psaper 6.3 ischaemic heart disease. 2013. http://www.who.int/medicines/areas/priority_medicines/BP6_3IHD.pdf. Accessed 5 June 2016.

18. Wise J. Polypill holds promise for people with chronic disease. Bull World Health Organ. 2005;83:885-7.

19. Wirtz VJ, Kaplan WA, Kwan GF, Laing RO. Access to medications for cardiovascular diseases in low- and middle-income countries. Circulation. 2016;133(21):2076-85

20. Guglietta A, Guerrero M. Issues to consider in the pharmaceutical development of a cardiovascular polypill. Nat Clin Pract Cardiovasc Med. 2009;6(2):112-9.

21. Neal B. Secondary prevention of cardiovascular disease: fixed dose combinations: a research agenda for the European Union Geneva: World Health Organization. 2004. https://www.google.ca/url?sa=t\&rct=j\&q=\&e $\mathrm{src}=\mathrm{s} \&$ source $=$ web $\& \mathrm{~cd}=4 \& \mathrm{cad}=\mathrm{rja} \&$ uact $=8 \& \mathrm{ved}=0 C D|Q F j A D \& u r|=h t t$ p\%3A\%2F\%2Farchives.who.int\%2Fprioritymeds\%2Freport\%2Fbackgroun d\%2Fcardiovascular.doc\&ei=OMaeVeGIBY2TyASXx7qoBg\&usg=AFQjCN HLRrIJImauiQOWN34mG9-ObLnO2Q\&sig2=tShDSOL-RH8DRKEK9vKq4g. Accessed 5 June 2016.

22. Kaplan W. Fixed dose combinations as an innovative delivery mechanism Geneva: World Health Organization. 2004. https://www.google.ca/url?sa $=t \& r c t=j \& q=\& e s r c=s \&$ source $=$ web\& $c d=4 \& c a d=r j \&$ uact $=8 \&$ ved $=0 C$ DAQFjAD\&url=http\%3A\%2F\%2Fapps.who.int\%2Fmedicinedocs\%2Fdoc uments\%2Fs20244en\%2Fs20244en.pdf\&ei=ScaeVaqRJIOpyASFion4Bg\& usg=AFQjCNFPkU45PSWX4ELOtgUMof2W6-BWbw\&sig2=rwrKlj0kUXW r2B_O9WoYkA. Accessed 5 June 2016.

23. Cavicchi JR, Kowalski SP. Report of patent literature, search methodology and patent status of medicines on the WHO EML. International Technology Transfer Institute, Franklin Pierce Center for Intellectual Property, 2009.

24. Cavicchi JR, Kowalski SP. Preliminary report on search methodology and patent status of medicines added to the WHO EML from the 18th meeting of the WHO expert committee on the selection and use of essential medicines. University of New Hampshire, 2011.

25. Mackey TK, Liang BA. Patent and exclusivity status of essential medicines for non-communicable disease. PLoS One. 2012;7(11):e51022.

26. Milani B, Oh C. Searching for patents on essential medicines in developing countries: a methodology. Int J Intellect Prop Manag. 2011:4(3):191-209.

27. United Nations Development Programme. Patent information and transparency: a methodology for patent searches on essential medicines in developing countries New York, NY: United Nations Development Programme. 2012. http://www.undp.org/content/undp/en/home/ librarypage/hiv-aids/a-methodology-for-patent-searches-on-essentialmedicines-in-deve.html. Accessed 5 June 2016.

28. World Health Organization South-East Asia Region. How to conduct patent searches for medicines. a step-by-step guide. 2010. http://apps.who. int/medicinedocs/en/d/Js17398e/. Accessed 5 June 2016.

29. Amin T. Patent landscape report for pegylated interferon alfa $2 \mathrm{~A}$ and 2B: initiative for medicines, access and knowledge (I-MAK). 2013. http:// www.i-mak.org/storage/I-MAK+Patent+Landscape+for+Pegylated+Int erferon+Alfa+2A+and+2B.pdf. Accessed 5 June 2016.
30. United States Food and Drug Administration. Orange book: approved drug products with therapeutic equivalence evaluations. 2016. http:// www.accessdata.fda.gov/scripts/cder/ob/default.cfm. Accessed 5 June 2016.

31. Health Canada. Patent register 2015. http://pr-rdb.hc-sc.gc.ca/pr-rdb/ start-debuter.do?lang=eng. Accessed 5 June 2016.

32. Health Canada. Drug product database online query. 2015. http://webprod5.hc-sc.gc.ca/dpd-bdpp/index-eng.jsp. Accessed 5 June 2016.

33. Office EP. EPO worldwide legal status database (INPADOC). 2016. https:// www.epo.org/searching-for-patents/legal/inpadoc.html. Accessed 5 June 2016.

34. Thomson Reuters. Derwent World Patents Index. 2015. http://thomsonreuters.com/en/products-services/intellectual-property/patent-researchand-analysis/derwent-world-patents-index.html. Accessed 5 June 2016.

35. Thomson Reuters. Thomson innovation 2015. http://info.thomsoninnovation.com/. Accessed 5 June 2016.

36. European Patent Office. The "extended" (INPADOC) patent family. 2008. http://www.epo.org/searching/essentials/patent-families/inpadoc.html. Accessed 5 June 2016.

37. World Intellectual Property Organization. Patentscope. 2015. http://www. wipo.int/patentscope/en/. Accessed 5 June 2016.

38. Sanz G, Castellano JM, Fuster V. Polypill: chimera or reality? Revista española de cardiología. 2014;67(09):689-92.

39. Hao J, Rodriguez-Monguio R, Seoane-Vazquez E. Fixed-dose combination drug approvals, patents and market exclusivities compared to single active ingredient pharmaceuticals. PLoS One. 2015;10(10):e0140708.

40. Royal Society of Chemistry. The Merck index 2015. https://www.rsc.org/ merck-index. Accessed 5 June 2016.

41. Beall RF, Kuhn R, Attaran A. Compulsory licensing often did not produce lower prices for antiretrovirals compared to international procurement. Health Aff. 2015;34(3):493-501.

42. Friedman MA, den Besten $\mathrm{H}$, Attaran A. Out-licensing: a practical approach for improvement of access to medicines in poor countries. Lancet. 2003;361(9354):341-4.

43. International Federation of Pharmaceutical Manufacturers and Associations. Policy position: voluntary licenses and non-assert declarations. 2015. http://www.ifpma.org/wp-content/uploads/2016/03/IFPMA-Position-on-VL-and-Non-Assert-Declarations-18FEB2015.pdf. Accessed 5 June 2016.

44. World Health Organization, UNAIDS. Accelerating access initiative. 2002. http://www.who.int/hiv/pub/prev_care/en/isbn9241210125.pdf. Accessed 5 June 2016.

45. Waning B, Kaplan W, King AC, Lawrence DA, Leufkens HG, Fox MP. Global strategies to reduce the price of antiretroviral medicines: evidence from transactional databases. Bull World Health Organ. 2009;87:520-8.

46. Beall RF, Attaran A, Kuhn R. Compulsory licenses: the authors reply. Health Aff. 2015;34(6):1068.

47. Beall R, Attaran A. Accelerating access to generic HIV medicines in developing countries that have granted patent protection (forthcoming). 2016.

\section{Submit your next manuscript to BioMed Central and we will help you at every step:}

- We accept pre-submission inquiries

- Our selector tool helps you to find the most relevant journal

- We provide round the clock customer support

- Convenient online submission

- Thorough peer review

- Inclusion in PubMed and all major indexing services

- Maximum visibility for your research

Submit your manuscript at www.biomedcentral.com/submit 